\title{
G894T and 4a/b Polymorphisms of NOS3 Gene are Not Associated with Cancer Risk: a Meta-analysis
}

\author{
Shafiul Haque ${ }^{1,2}$, Raju K Mandal ${ }^{2}$, Naseem Akhter ${ }^{3}$, Aditya K Panda ${ }^{4}$, Arif \\ Hussain $^{5}$, Saif Khan ${ }^{6}$, Mohtashim Lohani ${ }^{7 *}$
}

\begin{abstract}
Endothelial nitric oxide synthase (eNOS or NOS3) produces nitric oxide and genetic polymorphisms of NOS3 gene play significant roles in various processes of carcinogenesis. The results from published studies on the association between NOS3 G894T and NOS3 intron $4(4 \mathrm{a} / \mathrm{b})$ polymorphisms and cancer risk are conflicting and inconclusive. However, i $\mathrm{n}$ order to assess this relationship more precisely, a meta-analysis was performed with PubMed (Medline), EMBASE and Google web searches until February 2014 to select all published casecontrol and cohort studies. Genotype distribution data were collected to calculate the pooled odd ratios (ORs) and 95\% confidence intervals (CIs) to evaluate the strength of association. A total of 10,546 cancer cases and 10,550 controls were included from twenty four case-control studies for the NOS3 G894T polymorphism. The results indicated no significant association with cancer risk as observed in allelic $(T$ vs $G$ : $O R=1.024,95 \% C I=0.954$ to $1.099, \mathrm{p}=0.508$ ), homozygous (TT $v$ S GG: $\mathrm{OR}=1.137,95 \% \mathrm{CI}=0.944$ to $1.370, \mathrm{p}=0.176$ ), heterozygous (GT vs GG: $\mathrm{OR}=0.993,95 \% \mathrm{CI}=0.932$ to $1.059, \mathrm{p}=\mathbf{0 . 8 3 5}$ ), recessive ( $\mathrm{TT}$ vs $\mathrm{GG}+\mathrm{GT}$ : $\mathrm{OR}=1.100,95 \% \mathrm{CI}=\mathbf{0 . 9 3 6}$ to 1.293 , $\mathrm{p}=0.249$ ) and dominant (TT+GT vs GG: $\mathrm{OR}=1.012,95 \% \mathrm{CI}=0.927$ to $1.105, \mathrm{p}=0.789$ ) genetic models. Similarly, a total of 3,449 cancer cases and 3,691 controls were recruited from fourteen case-control studies for NOS3 4a/b polymorphism. Pooled results indicated no significant association under allelic (A vs $\mathrm{B}$ : $\mathrm{OR}=0.981,95 \% \mathrm{CI}=0.725$ to 1.329, $\mathrm{p}=\mathbf{0 . 9 0 2}$ ), homozygous (AA vs $\mathrm{BB}$ : $\mathrm{OR}=1.166,95 \% \mathrm{CI}=\mathbf{0 . 5 2 4}$ to 2.593 , $\mathrm{p}=\mathbf{0 . 7 0 7}$ ), heterozygous (BA vs

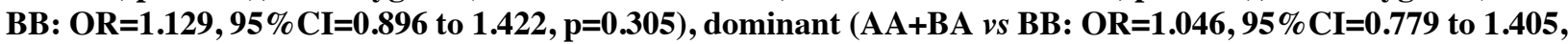
$\mathrm{p}=\mathbf{0 . 7 6 3}$ ) and recessive (AA vs $\mathrm{BB}+\mathrm{BA}: \mathrm{OR}=1.196,95 \% \mathrm{CI}=\mathbf{0 . 5 8 7}$ to $2.439, \mathrm{p}=\mathbf{0 . 6 2 2}$ ) genetic contrast models. This meta-analysis suggests that G894T and $4 \mathrm{a} / \mathrm{b}$ polymorphisms of NOS3 gene are not associated with increased or decreased risk of overall cancer.
\end{abstract}

Keywords: Meta-analysis - NOS3 - eNOS - cancer - polymorphism - susceptibility

Asian Pac J Cancer Prev, 16 (7), 2929-2937

\section{Introduction}

Cancer is an ever dreadful disease and shown major impact on human health problem linked with very high morbidity and mortality across the globe (Jemal et al., 2011). Its increasing incidence and mortality rate during the last two decades poses a big challenge in front of clinicians and scientists, across the world. Now, it is well established that several steps occur in cancer morphology, for e.g., local invasion, angiogenesis, intravasation in to the vasculature, extravasation and proliferation at a distant site. The precise etiology of this fatal disease is still unclear, it has been suggested that low penetrance genes interplay with environmental factors is a major cause of increasing risk of cancer (Lichtenstein et al., 2000). Therefore, it is predicted that the identification of host genetic factors for susceptibility to cancer would greatly help the overall control and therapeutic strategies of this deadly disease.

The free radical nitric oxide (NO) is a pleiotropic molecule primarily synthesized during the conversion of L-arginine to L-citrulline by endothelial nitric oxide synthase (eNOS), which is also known as nitric oxide synthase 3 (NOS3) or constitutive NOS (cNOS) (Forstermann et al., 1998). NO has various physiological and pathological functions, which includes vasodilatation, smooth muscle relaxation, immunity and carcinogenesis (Moncada et al., 1991). A constitutive $\mathrm{Ca}^{2+}$ dependent NOS3 provides a basal release of NO. NOS3 is associated with plasma membranes surrounding cells and the membranes of Golgi bodies within cells. Tumor growth and metastasis are mainly depend upon tumor

${ }^{1}$ Department of Biosciences, Jamia Millia Islamia (A Central University), New Delhi, ${ }^{4}$ Centre for Life Science, School of Natural Sciences, Central University of Jharkhand, Ranchi, Jharkhand, ${ }^{7}$ Department of Biosciences, Integral University, Lucknow, Uttar Pradesh, India, ${ }^{2}$ Research and Scientific Studies Unit, College of Nursing and Allied Health Sciences, Jazan University, Jazan, ${ }^{3}$ Department of Laboratory Medicine, Faculty of Applied Medical Sciences, Albaha University, Albaha, ${ }^{6}$ Department of Clinical Nutrition, College of Applied Medical Sciences, University of Ha'il, Ha 'il, Saudi Arabia, ${ }^{5}$ School of Life Sciences, Manipal University, Dubai International Academic City, Dubai, United Arab Emirates*For correspondence: mlohani@rediffmail.com 
angiogenesis and previous studies have suggested that NO generated by the NOS3 plays an important role in regulating cell death, angiogenesis, killing of tumor cells and reducing cell adhesion to endothelium (Kong et al., 1996; Umansky et al., 1997). The overproduction of NO causes DNA damage and inhibits DNA repair process (Chien et al., 2004).

NOS3 is an enzyme that in humans is encoded by the NOS3 gene (also called as eNOS gene), located on chromosome 7q36, encodes a protein of 1,203 amino acids (Accession No. AF519768), constitutively expressed in endothelial cells and vascular epithelium of the cancer cells (Xu et al., 1994; Fukumura et al., 2006). Earlier clinical observational studies have demonstrated a dysregulation of NOS3 expression in human cancers (Ying et al., 2007). Polymorphisms of the NOS3 gene are very important in the angiogenesis pathway and have also been found to have functional and clinical significance in malignancies. Till date many polymorphisms have been reported in NOS3 gene, among them G894T polymorphism (rs1799983), which is located in exon 7 of the NOS3 gene and leads to the amino acid substitution from Glu298Asp that alters susceptibility to cleavage, and reduced enzyme activity and basal NO production in NOS3 894T (298Asp) allele carriers compared with the GG homozygotes (Wang et al., 1997; Veldman et al., 2002). Another polymorphism, $4 \mathrm{a} / \mathrm{b}$ is a $27 \mathrm{bp}$ variable number of tandem repeats (VNTR) polymorphism in intron 4 of NOS3 gene has two variants with four (variant "a") or five (variant "b") tandem repeats that may influence the gene activity (Brankovic et al., 2013).

Having seen the diverse role of NOS3 in carcinogenesis, numbers of molecular epidemiological case-control studies have been investigated to interpret the possible association between G894T and 4a/b polymorphisms of NOS3 gene and human malignancies in different populations (Hefler et al., 2002; Medeiros et al., 2002; Ghilardi et al., 2003; Riener et al., 2004; Conde et al., 2006; Hefler et al., 2006; Lu et al., 2006; Royo et al., 2006; Lee et al., 2007; Yang et al., 2007; Jacobs et al., 2008; Li et al., 2009; Lee et al., 2009; Yeh et al., 2009; Tecder Unal et al., 2010; Zintzaras et al., 2010; Özturk et al., 2011; Ryk et al., 2011; Amasyali et al., 2012; Arıkan et al., 2012; Lee et al., 2012; Zhao et al., 2012; Branković et al., 2013; Cimponeriu et al., 2013; Jang et al., 2013; Safarinejad et al., 2013; Ramírez-Patiño et al., 2013; Verim et al., 2013; Yuan et al., 2013), but results were inconsistent and inconclusive. Inconsistency in the results could possibly be attributed to small sample size and low statistical power. Recently, Burton et al. suggested that larger sample sizes are good to study the genetic associations with complex diseases (Burton et al., 2009). Thus, these findings prompted us to perform this meta-analysis to pool all pertinent published studies to evaluate the more precise association and understanding the role NOS3 G894T and NOS3 4a/b polymorphisms in cancer development. Till now, no meta-analysis has been performed to reliably evaluate these polymorphisms with overall cancer susceptibility. A meta-analysis is an important statistical tool because it uses quantitative approach to pool the data from individual studies where individual sample sizes are small with low statistical power, and delivers robust conclusion (Cohn and Becker, 2002; Mandal et al., 2013).

\section{Materials and Methods}

\section{Identification and eligibility of pertinent studies}

We searched electronic form of research articles from PubMed (Medline), EMBASE and Google Scholar web databases (last search updated on April 2014) with the combination of following key words: 'endothelial nitric oxide synthase' or 'eNOS' or 'nitric oxide synthase 3' or 'NOS3' or 'constitutive NOS' or 'cNOS' polymorphism or variant or mutation AND cancer risk or susceptibility and/or tumor risk or susceptibility'. The search was focused and limited to the published studies that had been conducted in humans. All retrieve articles were examined by reading the titles and abstracts, and all published studies matching with the eligible criteria were retrieved for this meta-analysis. We also performed manual search for the references listed in the retrieve articles for other eligible articles.

\section{Inclusion and exclusion criteria}

Articles included in the current meta-analysis had to meet all the following criteria: a) must evaluated the association between NOS3 G894T and/or NOS3 4a/b polymorphism and cancer risk, b) must used a case-control study design, c) recruited histologically confirmed cancer patients and healthy controls, d) have available genotype frequency in case and control,e) published in the English language. In addition to above, when the same patient populations appeared in more than one publication, only the most recent or complete study was included. The major reasons for study exclusion were, overlapping of the data, case-only studies, review articles, and genotype frequencies or numbers not reported. The information pertaining to the selection (inclusion and exclusion criteria) of studies for this analysis is appended as Figure 1.

\section{Data extraction and quality assessment}

For each retrieved research study, the methodological quality assessment and data extraction were independently abstracted in duplicate copies by two independent investigators following a standard protocol. Standard data-collection form was used to ensure the precision of the collected data by strictly following the selection (inclusion and exclusion) criteria mentioned above. The main characteristics abstracted from the retrieved studies included the name of the first author, publication year, the country of origin, the number of cases and controls, type of cancer, genotyping source and genotype frequencies for cases and controls. Cases related with disagreement on any item of the collected data from the selected studies were fully debated with investigators to achieve a final consensus.

\section{Statistical analysis}

The actual strength of association between NOS3 G894T and NOS3 intron 4VNTR (4a/b) polymorphisms and cancer risk was evaluated by calculating the pooled odd ratios (ORs) and their corresponding $95 \%$ confidence 
G894T and 4a/b Polymorphisms of NOS3 Gene are Not Associated with Cancer Risk - a Meta-analysis

intervals (CIs) (Woolf, 1955). Heterogeneity assumption between studies across the eligible comparison was performed by the chi-square based Q-test ( $\mathrm{Wu}$ and $\mathrm{Li}$, 1999). Heterogeneity significance level was maintained at $p$-value $<0.05$ to avoid underestimation of the presence of heterogeneity. A fixed effect model (if $\mathrm{p}>0.05$ ) (Mantel and Haenszel, 1959) or a random effect model (if $\mathrm{p}<0.05$ ) (DerSimonian and Laird, 1986) was applied for pooling the data from individual studies. Moreover, $\mathrm{I}^{2}$ statistics was also used to efficiently verify the heterogeneity (Higgins et al., 2003). Hardy-Weinberg equilibrium (HWE) in the controls was calculated via chi-square based test. Funnel plot asymmetry was determined by Egger's linear regression test which is a type of linear regression approach to measure the funnel plot asymmetry on the natural logarithm scale of the OR. The significance of the intercept was measured by the t-test (statistically significant publication bias was considered at p-value $<0.05$ ) (Egger et al., 1997). To choose the most pertinent software program to carry out the current meta-analysis, an online comparison of 'meta-analysis' programs was done using url http://www.meta-analysis.com/pages/ comparisons.html. All statistical evaluations were performed by Comprehensive Meta-Analysis (CMA) V2 Software program (Biostat Inc., USA). All p-values were two sided and statistical significance level was considered as p-value $<0.05$ for the present meta-analysis.

\section{Results}

\section{Literature search and meta-analysis databases}

According to the inclusion criteria, a total of twenty nine research articles were finally included in this metaanalysis through literature search from the PubMed
(Medline), EMBASE and Google Scholar web databases for NOS3 G894T and NOS3 4a/b polymorphisms. All retrieved articles were critically examined by reading the titles and abstracts, and the full texts for the potentially relevant publications were further reviewed for their aptness for this meta-analysis.

Research articles either showing NOS3 G894T and/or NOS3 4a/b polymorphisms to predict survival in cancer patients or considering NOS3 variants as an indicator for response to therapy were excluded straightaway from this meta-analysis. Likewise, research studies investigating the levels of NOS3 mRNA or protein expression or relevant review articles were also excluded from the analysis. We included only case-control or cohort design study based research articles having frequency of all three genotypes. Besides the online web database search, the references listed in the selected articles were also checked for other potential research studies. Major characteristics of the included studies and distributions of genotypes, minor allele frequency (MAF) in the controls and cases have been presented in Tables 1-4.

\section{Publication bias}

The Begg's funnel plot and Egger's test were carried out to test the publication bias among the included studies for the present meta-analysis. The appearance of the shape of funnel plots and the results of Egger's test have not shown the evidence of publication bias in all the five studied genetic models of NOS3 G894T (Table 5) and NOS3 4a/b polymorphisms (Table 6).

\section{Evaluation of heterogeneity}

In order to test heterogeneity among the selected research articles, Q-test and $\mathrm{I}^{2}$ statistics were employed.

Table 1. Major Characteristics of NOS3 G894T Studies Included in the Present Meta-analysis

\begin{tabular}{|c|c|c|c|c|c|c|}
\hline $\begin{array}{l}\text { First authors and } \\
\text { year of publication }\end{array}$ & $\begin{array}{l}\text { Type of } \\
\text { Cancer }\end{array}$ & Country & $\begin{array}{l}\text { Study } \\
\text { design }\end{array}$ & $\begin{array}{l}\text { Genotyping } \\
\text { method }\end{array}$ & Controls & Cases \\
\hline Brankovic et al. 2013 & Prostate & Serbia & HB & PCR-RFLP & 100 & 150 \\
\hline Safarinejad et al. 2013 & Prostate & Iran & HB & PCR-RFLP & 340 & 170 \\
\hline Jang et al. 2013 & Colorectal & Korea & HB & PCR-RFLP & 509 & 528 \\
\hline Verim et al. 2013 & Bladder & Turkey & $\mathrm{HB}$ & PCR-RFLP & 88 & 66 \\
\hline Arikan et al. 2012 & Colorectal & Turkish & HB & PCR-RFLP & 99 & 84 \\
\hline Lee et al. 2012 & Breast & Korea & HB & SNP-ITTM & 503 & 495 \\
\hline Zhao et al. 2012 & Glioma & Chinese & $\mathrm{HB}$ & TaqMan & 377 & 376 \\
\hline Ryk et al. 2011 & Bladder & Sweden & PB & TaqMan & 164 & 359 \\
\hline Ozturket al. 2011 & Endometrial & Tureky & HB & PCR-RFLP & 60 & 89 \\
\hline Zintzaras et al. 2010 & Breast & USA & $\mathrm{HB}$ & PCR-RFLP & 131 & 306 \\
\hline Li et al. 2009 & Breast & USA & PB & TaqMan & 485 & 489 \\
\hline Lee et al. 2009 & Prostate & USA & PB & TaqMan & 1666 & 1185 \\
\hline Yeh et al. 2009 & Colorectal & Taiwan & $\mathrm{HB}$ & SNP detection kit & 736 & 727 \\
\hline Jacobs et al. 2008 & Prostate & USA & PB & TaqMan & 1446 & 1420 \\
\hline Lee et al. 2007 & Breast & Korea & HB & SNP-ITTM & 1211 & 1721 \\
\hline Yang et al. 2007 & Breast & USA & PB & TaqMan & 505 & 502 \\
\hline Conde et al. 2006 & Colorectal & Spain & PB & Pyro sequencing & 538 & 355 \\
\hline Hefler et al. 2006 & Breast & Austria & $\mathrm{HB}$ & PCR-RFLP & 244 & 269 \\
\hline Lu et al. 2006 & Breast & USA & PB & PCR-RFLP & 423 & 421 \\
\hline Royo et al. 2006 & Breast & Spain & PB & RT-PCR & 321 & 440 \\
\hline Riener et al. 2004 & Vulvar & Austria & HB & Sequencing & 227 & 68 \\
\hline Ghilardi et al. 2003 & Breast & Italy & PB & TaqMan & 91 & 71 \\
\hline Hefler et al. 2002 & Ovarian & Germany & $\mathrm{HB}$ & Sequencing & 133 & 130 \\
\hline Medeiros et al. 2002 & Prostate & Portugal & $\mathrm{HB}$ & PCR-RFLP & 153 & 125 \\
\hline
\end{tabular}

*HB $=$ Hospital based; $\mathrm{PB}=$ Population based 
Table 2. Main Characteristics of NOS3 Intron 4 (4a/b) Studies Included in the Meta-analysis

\begin{tabular}{lllccrr}
\hline First authors and year & $\begin{array}{l}\text { Type of } \\
\text { Cancer }\end{array}$ & Country & $\begin{array}{c}\text { Study } \\
\text { design }\end{array}$ & $\begin{array}{c}\text { Genotyping } \\
\text { method }\end{array}$ & Controls & Cases \\
\hline Cimponeriu et al. 2013 & Breast & Romania & HB & PCR & 100 & 150 \\
Safarinejad et al. 2013 & Prostate & Iran & HB & PCR & 340 & 170 \\
Yuan et al. 2013 & HCC & China & HB & PCR & 384 & 293 \\
Jang et al. 2013 & Colorectal & Korea & HB & PCR & 509 & 528 \\
Ramírez et al. 2013 & Breast & Mexico & PB & PCR & 280 & 428 \\
Amasyali et al. 2012 & Bladder & Turkey & HB & PCR & 202 & 123 \\
Ozturk et al. 2011 & Endometrial & Turkey & HB & PCR & 60 & 89 \\
Zintzaras et al. 2010 & Breast & Greece & HB & PCR & 131 & 306 \\
Tecder et al. 2010 & Gastric & Turkey & & PCR & 192 & 46 \\
Yeh et al. 2009 & Colorectal & Taiwan & HB & PCR & 736 & 727 \\
Hefler et al. 2006 & Breast & Austria & HB & PCR & 244 & 269 \\
Riener et al. 2004 & Vulvar & Austria & HB & PCR & 227 & 65 \\
Hefler et al. 2002 & Ovarian & Austria & HB & PCR & 133 & 130 \\
Medeiros et al. 2002 & Prostate & Portugal & HB & PCR & 153 & 125 \\
\hline
\end{tabular}

*HB= Hospital based; $\mathrm{PB}=$ Population based

Table 3. Genotypic Distribution of NOS3 G894T Gene Polymorphism Included in this Meta-analysis

\begin{tabular}{|c|c|c|c|c|c|c|c|c|c|}
\hline \multirow[t]{3}{*}{ Authors and year } & \multicolumn{4}{|c|}{ Controls } & \multicolumn{4}{|c|}{ Cancer cases } & \multirow{3}{*}{$\begin{array}{c}\text { HWE } \\
\text { p-value }\end{array}$} \\
\hline & \multicolumn{3}{|c|}{ Genotype } & \multirow{2}{*}{$\frac{\text { Minor allele }}{\text { MAF }}$} & \multicolumn{3}{|c|}{ Genotype } & \multirow{2}{*}{$\frac{\text { Minor allele }}{\text { MAF }}$} & \\
\hline & GG & GT & $\overline{\mathrm{TT}}$ & & $\overline{\mathrm{GG}}$ & GT & $\mathrm{TT}$ & & \\
\hline Brankovic et al. 2013 & 54 & 40 & 6 & 0.26 & 76 & 65 & 9 & 0.27 & 0.69 \\
\hline Safarinejad et al. 2013 & 248 & 89 & 3 & 0.13 & 120 & 48 & 2 & 0.15 & 0.11 \\
\hline Jang et al. 2013 & 431 & 76 & 2 & 0.07 & 417 & 102 & 9 & 0.11 & 0.48 \\
\hline Verim et al. 2013 & 31 & 44 & 13 & 0.39 & 7 & 49 & 10 & 0.52 & 0.68 \\
\hline Arikan et al. 2012 & 27 & 50 & 22 & 0.47 & 35 & 42 & 7 & 0.33 & 0.89 \\
\hline Lee et al. 2012 & 481 & 82 & 0 & 0.07 & 431 & 60 & 4 & 0.06 & 0.06 \\
\hline Zhao et al. 2012 & 278 & 84 & 15 & 0.15 & 282 & 77 & 17 & 0.14 & 0.01 \\
\hline Ryk et al. 2011 & 75 & 62 & 13 & 0.29 & 128 & 106 & 28 & 0.3 & 0.97 \\
\hline Ozturket al. 2011 & 47 & 31 & 11 & 0.29 & 42 & 18 & 0 & 0.15 & 0.11 \\
\hline Zintzaras et al. 2010 & 12 & 50 & 38 & 0.63 & 15 & 46 & 39 & 0.62 & 0.46 \\
\hline Li et al. 2009 & 236 & 209 & 40 & 0.29 & 242 & 200 & 47 & 0.3 & 0.57 \\
\hline Lee et al. 2009 & 594 & 486 & 103 & 0.29 & 887 & 645 & 134 & 0.27 & 0.8 \\
\hline Yeh et al. 2009 & 575 & 143 & 10 & 0.11 & 568 & 124 & 10 & 0.1 & 0.74 \\
\hline Jacobs et al. 2008 & 682 & 600 & 164 & 0.32 & 659 & 632 & 129 & 0.31 & 0.06 \\
\hline Lee et al. 2007 & 792 & 151 & 1 & 0.08 & 1134 & 203 & 11 & 0.08 & 0.02 \\
\hline Yang et al. 2007 & 199 & 176 & 34 & 0.29 & 204 & 168 & 44 & 0.3 & 0.57 \\
\hline Conde et al. 2006 & 216 & 235 & 87 & 0.38 & 135 & 160 & 60 & 0.39 & 0.08 \\
\hline Hefler et al. 2006 & 118 & 109 & 17 & 0.29 & 118 & 117 & 34 & 0.34 & 0.22 \\
\hline Lu et al. 2006 & 199 & 186 & 38 & 0.3 & 189 & 193 & 39 & 0.32 & 0.55 \\
\hline Royo et al. 2006 & 130 & 146 & 45 & 0.36 & 167 & 205 & 68 & 0.38 & 0.69 \\
\hline Riener et al. 2004 & 105 & 108 & 14 & 0.29 & 40 & 21 & 7 & 0.25 & 0.04 \\
\hline Ghilardi et al. 2003 & 39 & 47 & 5 & 0.31 & 26 & 36 & 9 & 0.38 & 0.05 \\
\hline Hefler et al. 2002 & 60 & 61 & 12 & 0.31 & 58 & 57 & 15 & 0.33 & 0.52 \\
\hline Medeiros et al. 2002 & 70 & 65 & 18 & 0.33 & 49 & 61 & 15 & 0.36 & 0.62 \\
\hline
\end{tabular}

$\mathrm{MAF}=$ Minor allele frequency; HWE $=$ Hardy Weinberg equilibrium

For NOS3 G894T polymorphism, significant heterogeneity was found in four genetic models viz. (T vs G; TT vs GG; TT+GT vs GG; TT vs GG+GT) (Table 5). Similarly, for NOS3 $4 \mathrm{a} / \mathrm{b}$ polymorphism, heterogeneity between the studies was statistically significant in all four genetic models. Therefore for statistically significant heterogeneity, we used random effect model to synthesize the data (Table 6).

\section{Sensitivity analysis}

Sensitivity analysis was performed by sequentially deleting each study to evaluate the effect of single study and assess the stability of the present meta-analysis. The results of sensitivity analysis indicated that pooled ORs before and after exclusion of the study which probably contributes the heterogeneity were generally similar (Figure 2: Sensitivity analysis for NOS3 G894T; Figure 3: Sensitivity analysis for NOS3 $4 \mathrm{a} / \mathrm{b}$ ). Hence, the results of the meta-analysis are relatively stable and convincing and no individual study significantly affected the pooled ORs.

Association of G894T and 4a/b polymorphisms of NOS3 gene and overall cancer susceptibility

We pooled all eligible case-control studies together for examining the overall association between NOS3 G894T and NOS3 $4 \mathrm{a} / \mathrm{b}$ polymorphisms and cancer risk. For NOS3 
G894T and 4a/b Polymorphisms of NOS3 Gene are Not Associated with Cancer Risk - a Meta-analysis Table 4. Genotypic Distribution of NOS3 4a/b Gene Polymorphism Included in this Meta-analysis

\begin{tabular}{|c|c|c|c|c|c|c|c|c|c|}
\hline \multirow[t]{3}{*}{ Authors and year } & \multicolumn{4}{|c|}{ Controls } & \multicolumn{4}{|c|}{ Cancer cases } & \multirow{3}{*}{$\begin{array}{c}\text { HWE } \\
\text { p-value }\end{array}$} \\
\hline & \multicolumn{3}{|c|}{ Genotype } & \multirow{2}{*}{$\frac{\text { Minor allele }}{\text { MAF }}$} & \multicolumn{3}{|c|}{ Genotype } & \multirow{2}{*}{$\frac{\text { Minor allele }}{\text { MAF }}$} & \\
\hline & BB & $\overline{\mathrm{BA}}$ & $\overline{\mathrm{AA}}$ & & $\overline{\mathrm{BB}}$ & $\mathrm{BA}$ & $\mathrm{AA}$ & & \\
\hline Componeriu et al. 2013 & 65 & 32 & 3 & 0.19 & 63 & 33 & 4 & 0.2 & 0.69 \\
\hline Safarinejad et al. 2013 & 249 & 88 & 3 & 0.13 & 101 & 54 & 15 & 0.24 & 0.11 \\
\hline Yuan et al. 2013 & 288 & 94 & 2 & 0.12 & 231 & 59 & 3 & 0.11 & 0.05 \\
\hline Jang et al. 2013 & 409 & 98 & 2 & 0.1 & 434 & 87 & 7 & 0.09 & 0.12 \\
\hline Ramírez et al. 2013 & 244 & 34 & 2 & 0.07 & 331 & 94 & 3 & 0.12 & 0.5 \\
\hline Amasyali et al. 2012 & 137 & 59 & 5 & 0.17 & 52 & 63 & 8 & 0.32 & 0.64 \\
\hline Ozturket al. 2011 & 1 & 16 & 43 & 0.85 & 10 & 31 & 48 & 0.71 & 0.72 \\
\hline Zintzaras et al. 2010 & 59 & 37 & 4 & 0.23 & 70 & 27 & 3 & 0.16 & 0.54 \\
\hline Tecder et al. 2010 & 66 & 28 & 98 & 0.58 & 35 & 10 & 1 & 0.13 & 0.001 \\
\hline Yeh et al. 2009 & 605 & 112 & 6 & 0.08 & 591 & 115 & 7 & 0.09 & 0.74 \\
\hline Hefler et al. 2006 & 193 & 75 & 2 & 0.14 & 196 & 68 & 5 & 0.14 & 0.06 \\
\hline Riener et al. 2004 & 171 & 53 & 3 & 0.12 & 48 & 17 & 0 & 0.13 & 0.62 \\
\hline Hefler et al. 2002 & 97 & 34 & 2 & 0.14 & 90 & 40 & 0 & 0.15 & 0.61 \\
\hline Medeiros et al. 2002 & 121 & 29 & 3 & 0.11 & 87 & 32 & 6 & 0.17 & 0.42 \\
\hline
\end{tabular}

$\overline{\mathrm{MAF}}=$ Minor allele frequency; HWE= Hardy Weinberg equilibrium

Table 5. Statistics to Test Publication Bias and Heterogeneity of NOS3 G894T in the Prik meta-analysis

\begin{tabular}{|c|c|c|c|c|c|c|c|}
\hline \multirow[t]{2}{*}{ Comparisons } & \multicolumn{3}{|c|}{ Egger's regression analysis } & \multicolumn{3}{|c|}{ Heterogeneity analysis } & \multirow{2}{*}{$\begin{array}{l}\text { Model used for } \\
\text { the meta-analysis }\end{array}$} \\
\hline & Intercept & $95 \% \mathrm{CI}$ & $\mathrm{p}$-value & Q-value & $\mathrm{P}_{\text {heterogeneity }}$ & $\mathrm{I}^{2}(\%)$ & \\
\hline $\mathrm{T} v s \mathrm{G}$ & 0.37 & -0.94 to 1.69 & 0.56 & 30.87 & 0.01 & 42.31 & Random \\
\hline TT vs GG & 0.96 & -0.008 to 1.94 & 0.07 & 40.32 & 0.01 & 42.95 & Random \\
\hline $\mathrm{GT} v s \mathrm{GG}$ & 0.2 & -0.94 to 1.40 & 0.72 & 33.85 & 0.06 & 32.06 & Fixed \\
\hline $\mathrm{TT}+\mathrm{GT} v s \mathrm{GG}$ & 0.32 & -0.93 to 1.58 & 0.59 & 38.02 & 0.02 & 39.52 & Random \\
\hline $\mathrm{TT} v s \mathrm{GG}+\mathrm{GT}$ & 0.94 & 0.01 to 1.86 & 0.06 & 35.61 & 0.04 & 35.42 & Random \\
\hline
\end{tabular}

Table 6. Statistics to Test Publication Bias and Heterogeneity of NOS3 4a/b in the Present meta-analysis

\begin{tabular}{|c|c|c|c|c|c|c|c|}
\hline \multirow[t]{2}{*}{ Comparisons } & \multicolumn{3}{|c|}{ Egger's regression analysis } & \multicolumn{3}{|c|}{ Heterogeneity analysis } & \multirow{2}{*}{$\begin{array}{l}\text { Model used for } \\
\text { the meta-analysis }\end{array}$} \\
\hline & Intercept & $95 \% \mathrm{CI}$ & p-value & Q-value & $\mathrm{P}_{\text {heterogeneity }}$ & $\mathrm{I}^{2}(\%)$ & \\
\hline A vs B & -4.11 & -10.05 to 1.81 & 0.15 & 104.84 & $<0.0001$ & 87.6 & Random \\
\hline AA vs BB & -3.84 & -7.26 to -0.41 & 0.05 & 43.27 & $<0.0001$ & 69.95 & Random \\
\hline BA vs BB & -0.3 & -3.42 to 2.82 & 0.83 & 41.52 & $<0.0001$ & 68.68 & Random \\
\hline $\mathrm{AA}$ vs $\mathrm{BA}+\mathrm{BB}$ & 0.05 & -2.97 to 3.08 & 0.96 & 42.49 & $<0.0001$ & 69.4 & Random \\
\hline $\mathrm{AA}+\mathrm{BA}$ vs $\mathrm{BB}$ & -1.71 & -5.77 to 2.34 & 0.37 & 72.48 & $<0.0001$ & 82.06 & Random \\
\hline
\end{tabular}

G894T, twenty four case-control studies (10546 cancer cases and 10550 controls) were included to evaluate the overall association of this polymorphism and cancer risk. We did not find any significant association in allelic ( $\mathrm{T} v \mathrm{~s}$ $\mathrm{G}$ : $\mathrm{OR}=1.024,95 \% \mathrm{CI}=0.954$ to $1.099, \mathrm{p}=0.508$ ) (Figure 4), homozygous (TT vs GG: $\mathrm{OR}=1.137,95 \% \mathrm{CI}=0.944$ to $1.370, \mathrm{p}=0.176$ ) (Figure 4), heterozygous (GT vs GG: $\mathrm{OR}=0.993,95 \% \mathrm{CI}=0.932$ to $1.059, \mathrm{p}=0.835$ ) (Figure 5), dominant (TT+GT vs GG: $\mathrm{OR}=1.012,95 \% \mathrm{CI}=0.927$ to 1.105, $\mathrm{p}=0.789$ ) (Figure 5) and recessive (TT vs GG+GT: $\mathrm{OR}=1.100,95 \% \mathrm{CI}=0.936$ to $1.293, \mathrm{p}=0.249)($ Figure 5) genetic models, respectively.

Similarly, we included fourteen case-control studies (3449 cancer cases and 3691 controls) for examining the association of NOS $34 \mathrm{a} / \mathrm{b}$ polymorphism and cancer risk. Like NOS3 G894T polymorphism, our meta-analysis did not provide any statistical significance of association between NOS3 $4 \mathrm{a} / \mathrm{b}$ polymorphism and cancer risk under allelic (A vs $\mathrm{B}$ : $\mathrm{OR}=0.981,95 \% \mathrm{CI}=0.725$ to 1.329, $\mathrm{p}=0.902$ ) (Figure 6), homozygous (AA vs BB: $\mathrm{OR}=1.166,95 \% \mathrm{CI}=0.524$ to $2.593, \mathrm{p}=0.707$ ) (Figure 6),

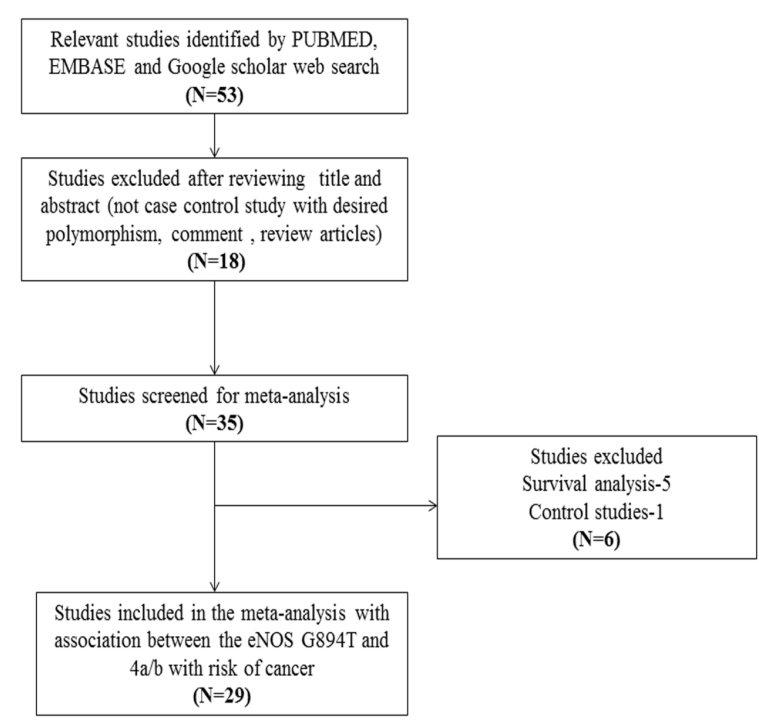

Figure 1. Flow Diagram Showing the Identification and Selection Criteria of the Studies Included for this Meta-analysis 


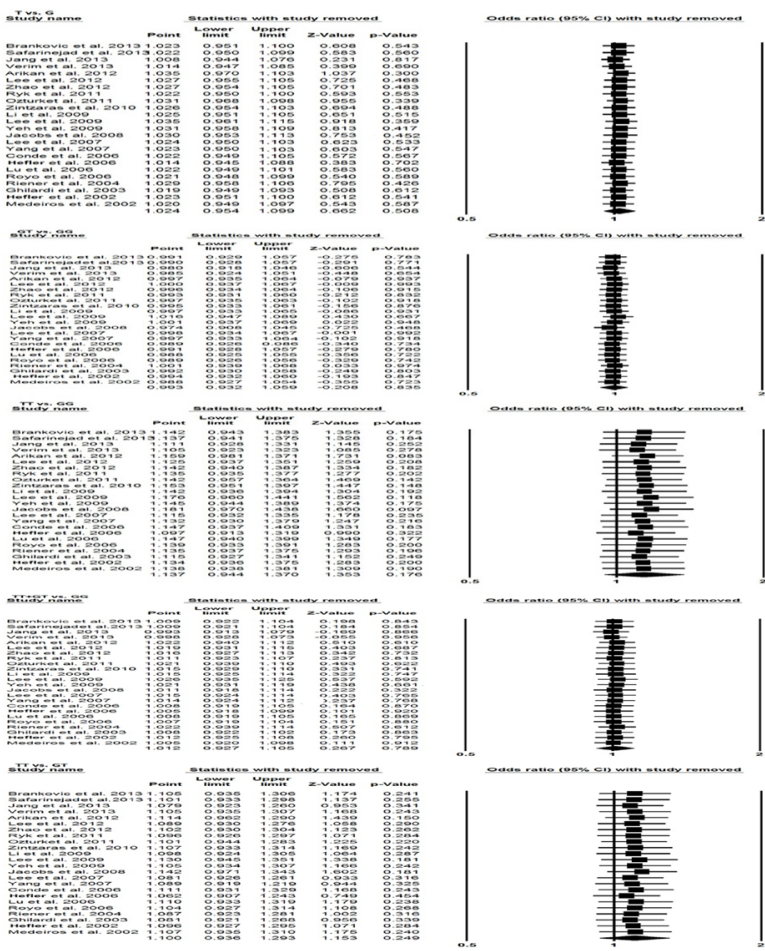

Figure 2. Sensitivity Analysis for NOS3 G894T

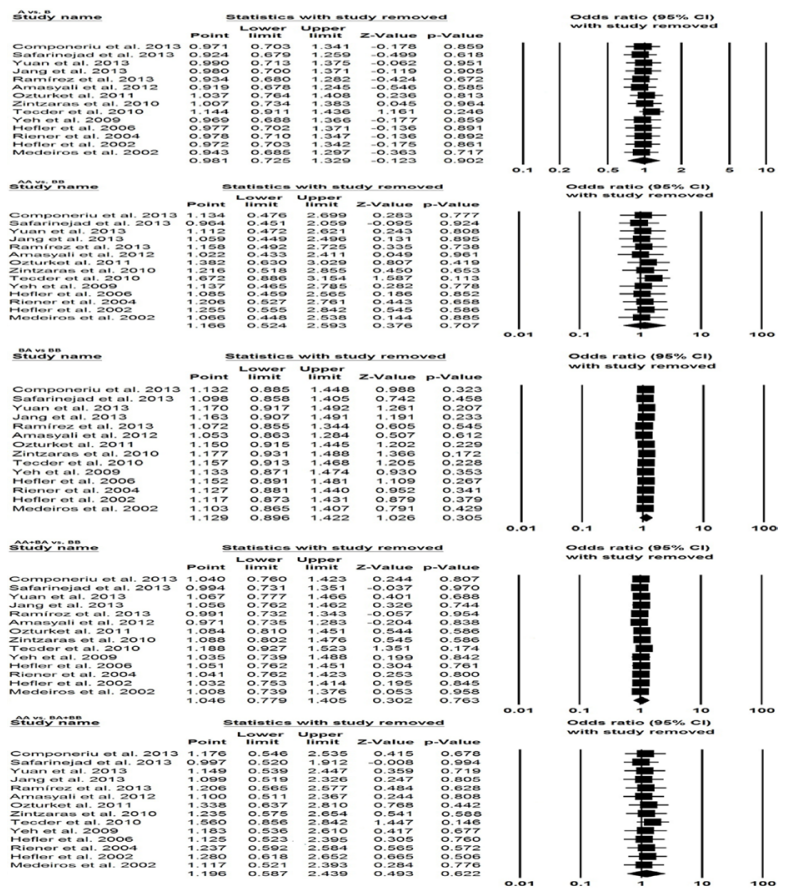

Figure 3. Sensitivity Analysis for NOS3 4a/b

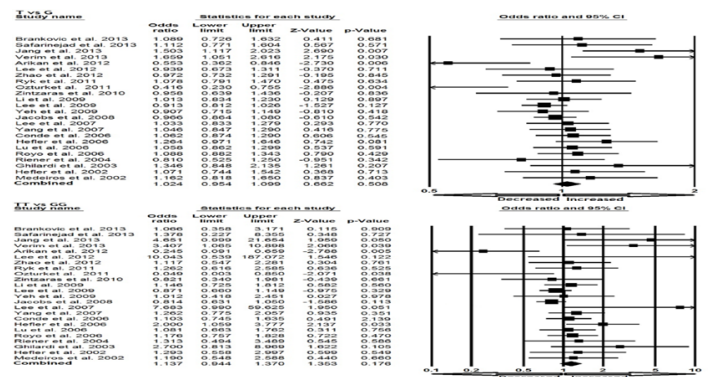

Figure 4. Forest Plot with ORs on Overall Cancer Risk Associated with NOS3 G894T Gene Polymorphism (T vs G; Allelic Model \& TT vs GG; Homozygous Model)

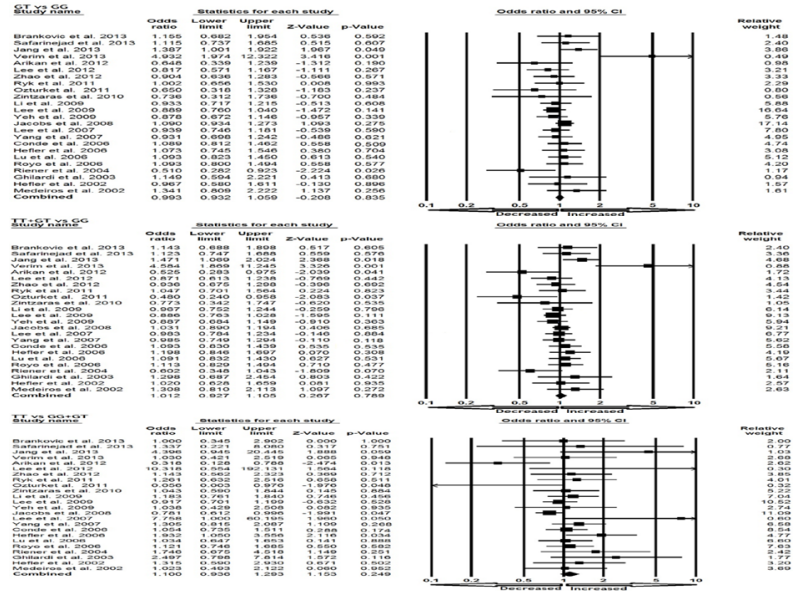

Figure 5. Forest Plot with ORs on Overall Cancer Risk Associated with NOS3 G894T Gene Polymorphism (GT vs GG; Heterozygous Model, TT+GT vs GG; dominant model and TT $v s$ GG+GT; recessive model)

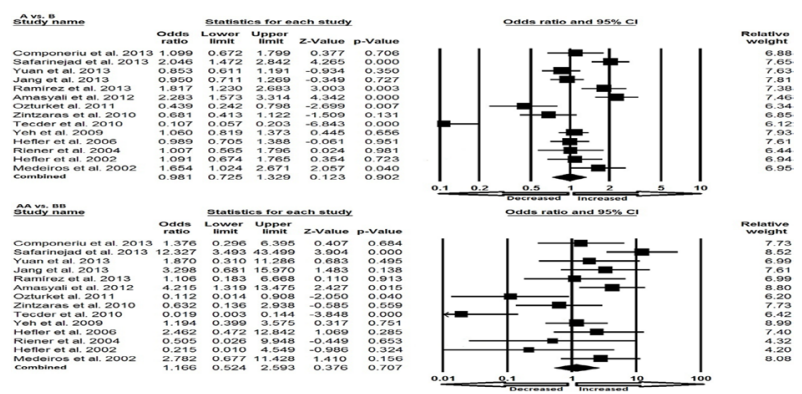

Figure 6. Forest Plot with ORs on Overall Cancer Risk Associated with NOS3 4a/b Gene Polymorphism (A vs B; Allelic Model \& AA vs BB; Homozygous Model)
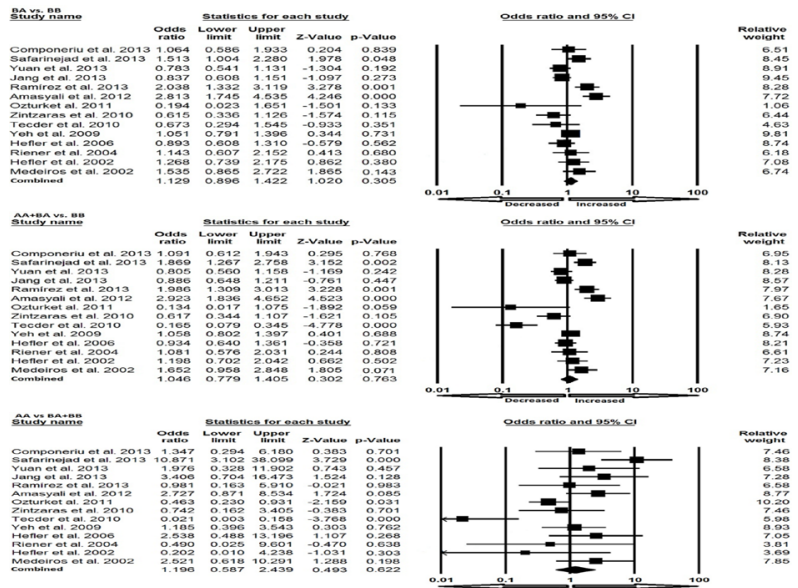

Figure 7. Forest Plot with ORs on Overall Cancer Risk Associated with NOS3 4a/b Gene Polymorphism (BA vs BB; Heterozygous model, AA+BA vs BB; Dominant Model and AA vs BB+BA; Recessive Model)

heterozygous (BA $v s \mathrm{BB}$ : $\mathrm{OR}=1.129,95 \% \mathrm{CI}=0.896$ to 1.422, $\mathrm{p}=0.305$ ) (Figure 7), dominant (AA+BA vs BB: $\mathrm{OR}=1.046,95 \% \mathrm{CI}=0.779$ to $1.405, \mathrm{p}=0.763)($ Figure 7$)$ and recessive $(\mathrm{AA} v s \mathrm{BB}+\mathrm{BA}: \mathrm{OR}=1.196,95 \% \mathrm{CI}=0.587$ to $2.439, \mathrm{p}=0.622$ ) (Figure 7) genetic contrast models.

\section{Discussion}

Cancer is a multifactorial dreadful disease involving 
G894T and 4a/b Polymorphisms of NOS3 Gene are Not Associated with Cancer Risk - a Meta-analysis

both environmental and genetic factors, till now the underlying molecular mechanism is unknown (Pharoah et al., 2004). It is well established that low-penetrating markers had garnered interest with regard to the study of the carcinogenesis. NO plays an important role in the relaxation of vascular smooth muscle, inhibits adhesion of platelets and leukocytes to the endothelium, and reduces vascular smooth muscle cells migration and proliferation as well as apoptosis depending on concentration and redox status of the cell (Schmidt and Walter, 1994).

Endothelial cells produce adhesion and soluble molecules that interact with various cancer cells. Production of NO by endothelial cells play important roles in regulating angiogenesis, killing tumour cells, and reducing tumour cell adhesion to endothelium (Kong et al., 1996; Umansky et al., 1997). Functional aberrations of NOS may reduce expression of NOS3 [53]. NO promotes tumor cell invasiveness by altering the balance between matrix metalloproteinase-2 (MMP2) and its inhibitors (Dimitrov et al., 1997). Also, it has been reported that NO is involved in Fas-L-mediated cytotoxicity (Garban and Bonavida, 1999). Hence, NOS3 efficiently can alter NO concentrations and hence has an effect on cytotoxic immune-defense mechanisms. These evidences suggest that NO may play a significant role in angiogenesis and the prominent role of NO in human carcinogenesis.

Based on the biological functions of NOS3, many researchers have hypothesized NOS3 gene as a "candidate gene" for cancer progression and evaluated the role of NOS3 G894T and NOS3 4a/b gene polymorphisms with risk of different malignancies in various ethnic groups. However, results of these independent studies were inconsistent. The lack of replication might be due to small sample size and low statistical power. Thus, we carried out this meta-analysis to appraise whether NOS3 G894T and NOS3 4a/b gene polymorphisms could have an impact on susceptibility to overall cancer. The present meta-analysis included the largest number of studies in order to rectify the spurious associations reflected from individual case-control studies.

This meta-analysis was based on the accumulation of all eligible data to analyze the overall cancer susceptibility. To the best of our knowledge, this is the first meta-analysis study investigating about the association of G894T and $4 \mathrm{a} / \mathrm{b}$ polymorphisms of NOS 3 gene and overall cancer risk. Our results revealed that NOS3 G894T and NOS3 $4 \mathrm{a} / \mathrm{b}$ polymorphisms have no role in increased or decreased risk of overall cancer. Similar trend of no association of NOS3 G894T polymorphism with risk of breast cancer was reported in the meta-analysis performed by Zintzaras et al. (2010). Earlier, Hao et al. (2010) reported significant association between NOS3 G894T polymorphism and breast cancer risk, but he included three ineligible studies, which was further corrected by the meta-analysis of $\mathrm{Fu}$ et al. (2011), where they excluded those three ineligible studies and found no association between NOS3 G894T polymorphism and breast cancer risk (Hao et al., 2010; Fu et al., 2011). A recent meta-analysis about the rs 1799983 and rs2070744 with 2,745 cases and 2,478 controls found no significant association for NOS3 G894T/rs1799983 with colorectal cancer risk (Chen et al., 2014).
$\mathrm{NO}$ is not always involved in the development of cancer, earlier studies suggest that NO may play antitumor growth and acts as a defense against metastasis of malignant tumors (Lala and Orucevic, 1998; Fujita et al., 2010). Studies from knockout mouse models showed that host-derived NO differentially modulate both tumor suppression and progression (Shi et al., 2000). Under specific conditions NO acts as an antitumor function by inducing tumor cell apoptosis (Wink et al., 1996). Interestingly, no positive association for the NOS3 gene or the $7 \mathrm{q} 36$ locus has been detected to date from the genome wide association studies (GWAS) of cancer risk (Hindorff et al., 2009). Nevertheless, whether NO acts as a tumor suppressor or promoter, it remains controversial. One of the possible explanations is that NOS3 gene has numerous SNPs distributed throughout the intron and exon region. Hence, it is possible that many alleles or genes contribute the susceptibility to cancer development and NOS3 G894T and NOS3 4a/b analyzed polymorphisms do not influence independently because they have been found in linkage disequilibrium (LD) with other causative germ-line polymorphisms. Meta-analysis of several gene-disease associations have shown that initially promising relationship often gravitate toward null over time (Ioannidis et al., 2001). As cancer shown polygenetic background, it seems reasonable to expect a variety of genes and genetic polymorphisms to be associated with the risk for and biology of this disease. Thus, a single genetic variant is usually inadequate to predict the risk of this complex disease.

Some limitations must be acknowledged while explaining the results; first, heterogeneity is an important issue when interpreting the results of meta-analysis. In the present study, we found inter-study heterogeneity. The source of heterogeneity may arise from many aspects, such as the region of study, the sample size, the case and the control group, clinical characteristics of different tumors, and the genotyping methodology. But, during sensitivity analysis where we omitted each study in a sequential manner included in this analysis and the results were not influenced by omission of single study and proved robust results. Second, the effect of gene-gene/ gene-environment interactions was not addressed in this meta-analysis. Third, although ethnicity plays an important role in cancer risk, we did not perform the further subgroup analysis by ethnicity because of limited number of studies for each type of cancer. Despite of above mentioned limitations, this study had some advantages, for e.g., an explicit and comprehensive search strategy based on computerassisted and manual search allowed all eligible studies to be included and no publication bias was detected in this meta-analysis and suggested robust results.

In conclusion, we can say that a meta-analysis is a useful approach of statistical data-analysis which summarizes both non-significant and significant data from individual studies and produces an accurate and precise conclusion. The overall outcomes of this meta-analysis suggested that NOS3 G894T and NOS3 4a/b polymorphisms could not alter susceptibility to overall cancer. However, large scale case-control studies with detailed individual information are needed to evaluate their association. Additionally, 
further well designed studies with the consideration of gene-gene and gene-environment interactions should be warranted to investigate their possible relationship. Here, we only analyzed the NOS3 G894T and NOS3 4a/b variants for overall cancer risk. In future, we will further try to explore the other relevant interactions to facilitate the discovery of the pathogenesis of cancer.

\section{Acknowledgements}

We thank Deanship of Scientific Research, Jazan University, Jazan, Saudi Arabia for providing the necessary facility for this research work and software related technical support for the statistical data analysis.

\section{References}

Amasyali AS, Kucukgergin C, Erdem S, et al (2012). Nitric oxide synthase (eNOS4a/b) gene polymorphism is associated with tumor recurrence and progression in superficial bladder cancer cases. J Urol, 188, 2398-403.

Arıkan S, Cacina C, Guler E, G, et al (2012). The effects of NOS3 Glu298Asp variant on colorectal cancer risk and progression in Turkish population. Mol Biol Rep, 39, 3245-9.

Branković A, Brajušković G, Nikolić Z, et al (2013). Endothelial nitric oxide synthase gene polymorphisms and prostate cancer risk in Serbian population. Int J Exp Pathol, 94, 355-61.

Burton PR, Hansell AL, Fortier I, et al (2009). Size matters: just how big is BIG?: Quantifying realistic sample size requirements for human genome epidemiology. Int $J$ Epidemiol, 38, 263-73.

Chen Y, Li J, Guo Y et al. (2014). Nitric oxide synthase 3 gene variants and colorectal cancer: a meta-analysis. Asian Pac $J$ Cancer Prev, 15, 3811-5.

Chien YH, Bau DT, Jan KY (2004). Nitric oxide inhibits DNAadduct excision in nucleotide excision repair. Free Radic Biol Med, 36, 1011-7.

Cimponeriu D, Ion DA, Spandole1 S, et al (2013). Potential implication of genetic polymorphisms and Torque teno virus in poradic breast cancer. Romanian Biotechnological Letters, 18, 7889-96.

Cohn LD, Becker BJ (2002). How meta-analysis increases statistical power. Psychol Methods, 3, 243-53.

Conde MC, Ramirez-Lorca R, Lopez-Jamar JM, et al (2006). Genetic analysis of caveolin-1 and eNOS genes in colorectal cancer. Oncol Rep, 16, 353-9.

DerSimonian R, Laird N (1986). Meta-analysis in clinical trials. Control Clin Trials, 7, 177-188.

Dimitrov Y, Petitjean P, Hannedouche T (1997) Kidney and nitric oxide. Nephrologie, 18, 41-46.

Egger M, Davey-Smith G, Schneider M, Minder C (1997). Bias in meta-analysis detected by a simple, graphical test. $B M J$, 7109, 629-34.

Forstermann U, Boissel JP, Kleinert H (1998). Expressional control of the 'constitutive' isoforms of nitric oxide synthase (NOS I and NOS III). FASEB J, 12, 773-90.

Fu H, Zhang Y, Jin L, Ding Z (2011). Endothelial nitric oxide synthase (eNOS) G894T polymorphism is not associated with breast cancer risk: new evidence. Breast Cancer Res Treat, 128, 595-8.

Fujita S, Masago K, Hatachi Y, et al (2010). Genetic polymorphisms in the endothelial nitric oxide synthase gene correlate with overall survival in advanced non-small-cell lung cancer patients treated with platinum-based doublet chemotherapy. BMC Med Genet, 11, 167.

Fukumura D, Kashiwagi S, Jain RK (2006). The role of nitric oxide in tumour progression. Nat Rev Cancer, 6, 521-534.

Garban HJ, Bonavida B (1999). Nitric oxide sensitizes ovarian tumor cells to Fas-induced apoptosis. Gynecol Oncol, 73, 257-64.

Ghilardi G, Biondi ML, Cecchini F, et al (2003). Vascular invasion in human breast cancer is correlated to T-->786C polymorphism of NOS3 gene. Nitric Oxide, 9, 118-122.

Hao Y, Montiel R, Huang Y (2010). Endothelial nitric oxide synthase (eNOS) $894 \mathrm{G}>\mathrm{T}$ polymorphism is associated with breast cancer risk: a meta-analysis. Breast Cancer Res Treat, 124, 809-813.

Hefler LA, Grimm C, Lantzsch T, et al (2006). Polymorphisms of the endothelial nitric oxide synthase gene in breast cancer. Breast Cancer Res Treat, 98, 151-5.

Hefler LA, Ludwig E, Lampe D, et al (2002). Polymorphisms of the endothelial nitric oxide synthase gene in ovarian cancer. Gynecol Oncol, 86, 134-7.

Higgins JP, Thompson SG, Deeks JJ, Altman DG (2003). Measuring inconsistency in meta-analyses. $B M J, \mathbf{7 4 1 4}$, 557-60.

Hindorff LA, Sethupathy P, Junkins HA, et al (2009). Potential etiologic and functional implications of genome-wide association loci for human diseases and traits. Proc Natl Acad Sci USA, 106, 9362-7.

Ioannidis JP, Ntzani EE, Trikalinos TA, Contopoulos-Ioannidis DG (2001). Replication validity of genetic association studies. Nat Genet, 29, 306-9.

Jacobs EJ, Hsing AW, Bain EB, et al (2008). Polymorphisms in angiogenesis-related genes and prostate cancer. Cancer Epidemiol Biomarkers Prev, 17, 972-7.

Jang MJ, Jeon YJ, Kim JW, et al (2013). Association of eNOS polymorphisms $(-786 \mathrm{~T}>\mathrm{C}, 4 \mathrm{a} 4 \mathrm{~b}, 894 \mathrm{G}>\mathrm{T})$ with colorectal cancer susceptibility in the Korean population. Gene, 512, 275-81.

Jemal A, Bray F, Center MM, et al (2011). Global cancer statistics. CA Cancer J Clin, 61, 69-90.

Kong L, Dunn GD, Keefer LK, Korthuis RJ (1996). Nitric oxide reduces tumor cell adhesion to isolated rat postcapillary venules. Clin Exp Metastasis, 14, 335-43.

Lala PK, Orucevic A (1998). Role of nitric oxide in tumor progression: lessons from experimental tumors. Cancer Metastasis Rev, 17, 91-106.

Lee KM, Choi JY, Lee JE, et al (2007). Genetic polymorphisms of NOS3 are associated with the risk of invasive breast cancer with lymph node involvement. Breast Cancer Res Treat, 106, 433-438.

Lee KM, Kang D, Park SK, et al (2009). Nitric oxide synthase gene polymorphisms and prostate cancer risk. Carcinogenesis, 30, 621-5.

Lee SA, Lee KM, Yoo KY, et al (2012). Combined effects of antioxidant vitamin and NOS3 genetic polymorphisms on breast cancer risk in women. Clin Nutr, 31, 93-98.

Li Y, Ambrosone CB, McCullough MJ, et al (2009). Oxidative stress-related genotypes, fruit and vegetable consumption and breast cancer risk. Carcinogenesis, 30, 777-784.

Lichtenstein P, Holm NV, Verkasalo PK, et al (2000). Environmental and heritable factors in the causation of cancer--analyses of cohorts of twins from Sweden, Denmark, and Finland. N Engl J Med, 343, 78-85.

Lu J, Wei Q, Bondy ML, et al (2006). Promoter polymorphism $(-786 t>C)$ in the endothelial nitric oxide synthase gene is associated with risk of sporadic breast cancer in nonHispanic white women age younger than 55 years. Cancer, 107, 2245-53.

Mandal RK, Yadav SS, Panda AK (2014). Meta-analysis on the 
association of nucleotide excision repair gene XPD A751C variant and cancer susceptibility among Indian population. Mol Biol Rep, 41, 713-9.

Mantel N, Haenszel W (1959). Statistical aspects of the analysis of data from retrospective studies of disease. J Natl Cancer Inst, 4, 719-48.

Medeiros R, Morais A, Vasconcelos A, et al (2002). Endothelial nitric oxide synthase gene polymorphisms and genetic susceptibility to prostate cancer. Eur J Cancer Prev, 11, 343-50.

Moncada S, Palmer RM, Higgs EA (1991). Nitric oxide: physiology, pathophysiology, and pharmacology. Pharmacol Rev, 43, 109-42.

Nicolson GL (1989). Organ specificity of tumor metastasis: role of preferential adhesion, invasion and growth of malignant cells at specific secondary sites. Cancer Metastasis Rev, 7, 143-8.

Özturk E, Dikensoy E, Balat O, et al (2011). Association of endothelial nitric oxide synthase gene polymorphisms with endometrial carcinoma: a preliminary study. J TurkishGerman Gynecol Assoc, 12, 229-33.

Pharoah PD, Dunning AM, Ponder BA, Easton DF (2004). Association studies for finding cancer-susceptibility genetic variants. Nat Rev Cancer, 4, 850-60.

Ramírez-Patiño R, Figuera LE, Puebla-Pérez AM, et al (2013). Intron 4 VNTR $(4 \mathrm{a} / \mathrm{b})$ polymorphism of the endothelial nitric oxide synthase gene is associated with breast cancer in Mexican women. J Korean Med Sci, 28, 1587-94.

Riener EK, Hefler LA, Grimm C, et al (2004). Polymorphisms of the endothelial nitric oxide synthase gene in women with vulvar cancer. Gynecol Oncol, 93, 686-690.

Royo JL, Moreno-Nogueira JA, Galán JJ, et al (2006). Lack of association between NOS3 Glu298Asp and breast cancer risk: a case-control study. Breast Cancer Res Treat, 100, 331-3.

Ryk C, Wiklund NP, Nyberg T, de Verdier PJ (2011). Polymorphisms in nitric-oxide synthase 3 may influence the risk of urinary-bladder cancer. Nitric Oxide, 25, 338-43.

Safarinejad MR, Safarinejad S, Shafiei N, Safarinejad S (2013). Effects of the T-786C, G894T, and Intron 4 VNTR (4a/b) polymorphisms of the endothelial nitric oxide synthase gene on the risk of prostate cancer. Urol Oncol, 31, 1132-1140.

Schmidt HH, Walter U (1994). NO at work. Cell, 78, 919-25.

Shi Q, Xiong Q, Wang B, et al (2000). Influence of nitric oxide synthase II gene disruption on tumor growth and metastasis. Cancer Res, 60, 2579-83.

Tecder Unal M, Karabulut HG, Gumus-Akay G, et al (2010). Endothelial nitric oxide synthase gene polymorphism in gastric cancer. Turk J Gastroenterol, 21, 338-44.

Umansky V, Bucur M, Schirrmacher V, Rocha M (1997). Activated endothelial cells induce apoptosis in lymphoma cells. Int J Oncol, 10, 465-71.

Veldman BA, Spiering W, Doevendans PA, et al (2002). The Glu298Asp polymorphism of the NOS3 gene as a determinant of the baseline production of nitric oxide. $J$ Hypertens, 20, 2023-7.

Verim L, Toptas B, Ozkan NE, et al (2013). Possible relation between the NOS3 gene GLU298ASP polymorphism and bladder cancer in Turkey. Asian Pac J Cancer Prev, 14, 665-668.

Wang XL, Mahaney MC, Sim AS, et al (1997). Genetic contribution of the endothelial constitutive nitric oxide synthase gene to plasma nitric oxide levels. Arterioscler Thromb Vasc Biol, 17, 3147-53.

Wink DA, Hanbauer I, Grisham MB, et al (1996). Chemical biology of nitric oxide: regulation and protective and toxic mechanisms. Current Top Cell Regul, 34, 159-87.
Woolf B (1955). On estimating the relation between blood group and disease. Ann Hum Genet, 19, 251-3.

Wu R, Li B (1999). A multiplicative-epistatic model for analyzing interspecific differences in outcrossing species. Biometrics, 2, 355-65.

Xu W, Charles IG, Moncada S, et al (1994). Mapping of the genes encoding human inducible and endothelial nitric oxide synthase (NOS2 and NOS3) to the pericentric region of chromosome 17 and to chromosome 7 , respectively. Genomics, 21, 419-422.

Yang J, Ambrosone CB, Hong CC, et al (2007). Relationships between polymorphisms in NOS3 and MPO genes, cigarette smoking and risk of post-menopausal breast cancer. Carcinogenesis, 28, 1247-53.

Yeh CC, Santella RM, Hsieh LL, Sung FC, Tang R (2009). An intron 4 VNTR polymorphism of the endothelial nitric oxide synthase gene is associated with early-onset colorectal cancer. Int J Cancer, 124, 1565-71.

Ying L, Hofseth LJ (2007). An emerging role for endothelial nitric oxide synthase in chronic inflammation and cancer. Cancer Res, 67, 1407-10.

Yuan F, Zhang LS, Li HY, et al (2013). Influence of angiotensin I-converting enzyme gene polymorphism on hepatocellular carcinoma risk in China. DNA Cell Biol, 32, 268-73.

Zhao P, Zhao L, Zou P, et al (2012). Genetic oxidative stress variants and glioma risk in a Chinese population: a hospitalbased case-control study. BMC Cancer, 12, 617.

Zintzaras E, Grammatikou M, Kitsios GD, et al (2010). Polymorphisms of the endothelial nitric oxide synthase gene in breast cancer: a genetic association study and metaanalysis. J Hum Genet, 55, 743-8. 